\title{
Increasing venoarterial extracorporeal membrane oxygenation flow negatively affects left ventricular performance in a porcine model of cardiogenic shock
}

Petr Ostadal ${ }^{1 *}$, Mikulas Mlcek², Andreas Kruger', Pavel Hala', Stanislav Lacko², Martin Mates', Dagmar Vondrakova', Tomas Svoboda², Matej Hrachovina², Marek Janotka', Hana Psotova', Svitlana Strunina ${ }^{3}$, Otomar Kittnar ${ }^{2}$ and Petr Neuzil ${ }^{1}$

\begin{abstract}
Background: The aim of this study was to assess the relationship between extracorporeal blood flow (EBF) and left ventricular (LV) performance during venoarterial extracorporeal membrane oxygenation (VA ECMO) therapy.

Methods: Five swine (body weight $45 \mathrm{~kg}$ ) underwent VA ECMO implantation under general anesthesia and artificial ventilation. Subsequently, acute cardiogenic shock with signs of tissue hypoxia was induced. Hemodynamic and cardiac performance parameters were then measured at different levels of EBF (ranging from 1 to $5 \mathrm{~L} / \mathrm{min}$ ) using arterial and venous catheters, a pulmonary artery catheter and a pressure-volume loop catheter introduced into the left ventricle.

Results: Myocardial hypoxia resulted in a decline in mean ( \pm SEM) cardiac output to $2.8 \pm 0.3 \mathrm{~L} / \mathrm{min}$ and systolic blood pressure (SBP) to $60 \pm 7 \mathrm{mmHg}$. With an increase in EBF from 1 to $5 \mathrm{~L} / \mathrm{min}$, SBP increased to $97 \pm 8 \mathrm{mmHg}$ $(P<0.001)$; however, increasing EBF from 1 to $5 \mathrm{~L} /$ min significantly negatively influences several cardiac performance parameters: cardiac output decreased form $2.8 \pm 0.3 \mathrm{~L} / \mathrm{min}$ to $1.86 \pm 0.53 \mathrm{~L} / \mathrm{min}(\mathrm{P}<0.001)$, LV end-systolic volume increased from $64 \pm 11 \mathrm{~mL}$ to $83 \pm 14 \mathrm{~mL}(P<0.001)$, LV stroke volume decreased from $48 \pm 9 \mathrm{~mL}$ to $40 \pm 8 \mathrm{~mL}$ $(P=0.045)$, LV ejection fraction decreased from $43 \pm 3 \%$ to $32 \pm 3 \%(P<0.001)$ and stroke work increased from $2096 \pm 342 \mathrm{mmHg} \mathrm{mL}$ to $3031 \pm 404 \mathrm{mmHg} \mathrm{mL}(\mathrm{P}<0.001)$. LV end-diastolic pressure and volume were not significantly affected.
\end{abstract}

Conclusions: The results of the present study indicate that higher levels of VA ECMO blood flow in cardiogenic shock may negatively affect LV function. Therefore, it appears that to mitigate negative effects on LV function, optimal VA ECMO blood flow should be set as low as possible to allow adequate tissue perfusion.

Keywords: Extracorporeal membrane oxygenation, Extracorporeal life support, Cardiac performance, Left ventricle, Cardiogenic shock

\section{Background}

Extracorporeal membrane oxygenation (ECMO) in the venoarterial (VA) configuration is an established method

\footnotetext{
*Correspondence: ostadal.petr@gmail.com

${ }^{1}$ Cardiovascular Center, Na Homolce Hospital, 15030 Prague, Czech Republic

Full list of author information is available at the end of the article
}

for the treatment of severe and rapidly progressing cardiogenic shock or refractory cardiac arrest [1-3]. In these critical conditions, VA ECMO may even fully substitute for cardiac pumping and pulmonary gas exchange to maintain sufficient tissue perfusion with oxygenated blood. Although randomized prospective trials confirming this have yet to be performed, several retrospective 
studies and case series demonstrating favourable outcomes have been published [4-6].

During peripheral VA ECMO therapy, an inflow venous cannula is inserted into the right atrium and drains blood into the extracorporeal blood pump. Blood gases are then exchanged in the membrane oxygenator and the oxygenated blood is typically returned to the descending aorta through a femoral arterial outflow cannula. This VA ECMO setting offers partial or full circulatory support; however, it may be associated with specific consequences for the failing heart. The inflow component of the VA ECMO circuit decreases preload and partially or completely unloads the right heart, whereas the outflow component increases left ventricular afterload [7]. In cases of extremely compromised left ventricle systolic function combined with increased afterload and, possibly, persisting (or increasing) bronchial arterial circulation or aortic and mitral regurgitation, the failing left ventricle becomes overloaded, although the right ventricle may be fully unloaded [7-9]. Progressive distension of the overloaded left ventricle with subsequent severe pulmonary edema is a critical condition that often requires urgent intervention (e.g., left ventricular assist device implantation) [3, 7-10].

Although it is clear that increasing extracorporeal blood flow (EBF) may increase left ventricular afterload, current data regarding the relationship among EBF, central hemodynamics and left ventricular performance are insufficient. Several experimental and clinical studies have focused on the impairment of left ventricular function during ECMO in neonates with pulmonary hypertension [11-16]; however, data in the literature regarding adult individuals with cardiogenic shock are very limited [17]. The objective of the present study was, therefore, to describe hemodynamic and left ventricular performance changes resulting from a gradual increase in EBF during VA ECMO in a porcine model of cardiogenic shock.

\section{Methods}

The present study was approved by the Charles University 1st Medical School Institutional Animal Care and Use Committee and was performed at the Animal Laboratory, Department of Physiology, 1st Medical School, Charles University in Prague and Na Homolce Hospital, Prague, Czech Republic, in accordance with Act No 246/1992 Coll. on the protection of animals against cruelty. The investigation conforms to the Guide for the Care and Use of Laboratory Animals published by the US National Institutes of Health (NIH Publication No. 85-23, revised 1985).

\section{Animal model}

Five female swine (Sus scrofa domestica, landrace $\times$ large white crossbreed), 4-5 months of age, with a mean body weight of $45 \mathrm{~kg}$ were included in the experiment. After a $24 \mathrm{~h}$ fast, general anesthesia was induced by administration of midazolam $(0.3 \mathrm{mg} / \mathrm{kg}$ intramuscular $)$ and ketamine hydrochloride (15-20 $\mathrm{mg} / \mathrm{kg}$ intramuscular). Initial propofol and morphine boluses $(2 \mathrm{mg} / \mathrm{kg}$ intravenous [18] and $0.1-0.2 \mathrm{mg} / \mathrm{kg} \mathrm{IV}$, respectively) were administered, and animals were orotracheally intubated. Continuous IV infusions of propofol $(8-10 \mathrm{mg} / \mathrm{kg} / \mathrm{h}$ ) and morphine $(0.1-0.2 \mathrm{mg} / \mathrm{kg} / \mathrm{h}$ ) were used to maintain anesthesia. The doses were adjusted according to physiological parameters, photoreaction, corneal and palpebral reflexes, lacrimation and spontaneous movement. At the conclusion of the experiment, potassium chloride $(2 \mathrm{mEq} / \mathrm{kg})$, in conjunction with general anesthesia, was used to euthanize the animals.

Bilateral femoral (arterial and venous) and jugular approaches were used for multiple sheath insertions using the standard percutaneous Seldinger technique. An initial rapid IV infusion of $1000 \mathrm{~mL}$ normal saline was given after anesthesia induction, followed by a continuous IV drip at a rate of $100-500 \mathrm{~mL} / \mathrm{h}$ to reach and maintain a mean right atrial pressure of $5-7 \mathrm{mmHg}$ (at an EBF of $1 \mathrm{~L} / \mathrm{min})$. An unfractionated heparin bolus $(100 \mathrm{U} / \mathrm{kg}$ IV) was administered after sheath placement, followed by a continuous IV infusion of $50 \mathrm{U} / \mathrm{kg} / \mathrm{h}$ to maintain an activated clotting time of $180-250 \mathrm{~s}$. Values were monitored every hour using the Hemochron Junior + Microcoagulation System (ITC, USA).

Ventilation was provided by a Hamilton G5 ventilator (Hamilton Medical AG, Switzerland) set to the INTELLiVENT-Adaptive Support Ventilation mode. The ventilator was set to maintain an oxygen saturation $\left(\mathrm{SpO}_{2}\right)$ of 95-99\%, and an end-tidal $\mathrm{CO}_{2}$ pressure of $4.8-5.6 \mathrm{kPa}$.

\section{ECMO}

The ECMO circuit consisted of a Levitronix Centrimag console (Thoratec, USA), centrifugal pump, tubing set with HMO 70000 Adult Microporous Membrane Oxygenator with Softline Coating (MAQUET Cardiopulmonary AG, Germany) and a mechanical gas blender (Sechrist, USA). Biomedicus cannulae (Medtronic, USA) were introduced percutaneously using the standard Seldinger technique after repeated dilations of the femoral artery and vein. For the insertion of ECMO cannulas the larger diameter left or right femoral arteries and veins were used according to the preceding duplex ultrasound measurement. The venous inflow cannula $(21 \mathrm{Fr})$ was inserted into the right atrium (the tip position was verified by fluoroscopy) and the femoral arterial outflow cannula (15 Fr) was inserted into the femoral artery. Blood gas parameters were monitored continuously in the blood leaving the oxygenator $\left(\mathrm{CDI}^{\mathrm{TM}}\right.$ Blood Parameter Monitoring System 500, Terumo Cardiovascular Systems Corporation, USA). The oxygen/air flow 
was repeatedly adjusted to maintain $\mathrm{pO}_{2}$ and $\mathrm{pCO}_{2}$ in the ranges of $10-15 \mathrm{kPa}$ and $4.0-6.5 \mathrm{kPa}$, respectively, in blood leaving the oxygenator. The EBF was set to $1 \mathrm{~L} / \mathrm{min}$ until the start of the measurements. The circuit, console function and initial settings were controlled and directed by a perfusionist.

\section{Vital function and hemodynamic monitoring}

Arterial pressure was measured using standard invasive methods with pressure transducers (Truwave, Edwards Lifesciences, LLC, USA) through a pigtail catheter inserted into the aortic arch. A Swan-Ganz catheter was introduced via a femoral vein to the pulmonary artery and pulmonary cardiac output $\left({ }_{\mathrm{p}} \mathrm{CO}\right)$ was measured at the end of each level of EBF. Electrocardiography, heart rate (HR), invasive blood pressures (aortic arch and jugular vein), pulse oximetry, capnometry and invasive central venous oxygen saturation were continuously monitored in all animals (Monitor Life Scope TR, Nihon Kohden, Japan; and Vigilance II, Edwards Lifesciences, USA). Brain oxygenation levels were measured using near-infrared spectroscopy (INVOS Cerebral/Somatic Oximeter, Somanetics, USA).

\section{Pressure-volume analysis}

A pressure-volume (PV) conductance catheter (Scisense 7F VSL Pigtail, Transonic, USA) was introduced into the left ventricle from the left carotid artery through the aortic valve. The catheter was connected to the PV unit (Sciense ADV 500, Transonic, USA) and operated in admittance mode. Correct positioning was assessed radiographically by confirming optimal PV loop morphology. The volume was calibrated against pulmonary thermodilution (Combo $\mathrm{CCO}$ catheter, Edwards Lifesciences, USA) at baseline. The PV values were recorded continually during the experiment, and data from five end-expiration loops at the end of each level of EBF were averaged and used for the analysis. Collected data included end-diastolic pressure (EDP), end-diastolic volume (EDV), systolic blood pressure (SBP), end-systolic volume (ESV) and stroke work (SW) (Fig. 1).

\section{Calculated parameters}

Stroke volume (SV) was calculated as SV $=$ EDV - ESV; left ventricular ejection fraction (LVEF) was calculated as $\mathrm{LVEF}=\mathrm{SV} / \mathrm{EDV}$; left ventricular cardiac output $\left({ }_{\mathrm{LV}} \mathrm{CO}\right)$ was calculated as ${ }_{\mathrm{LV}} \mathrm{CO}=\mathrm{SV} \times \mathrm{HR}$; recirculation minute volume $(\mathrm{RecV})$ was calculated as $\mathrm{RecV}={ }_{\mathrm{LV}} \mathrm{CO}-{ }_{\mathrm{p}} \mathrm{CO}$; and recirculation fraction (RecF) was calculated as $\operatorname{RecF}=\operatorname{RecV} /{ }_{\mathrm{LV}} \mathrm{CO}$.

\section{Cardiogenic shock induction}

The most frequently used model of acute cardiogenic shock in large animals is coronary artery occlusion,

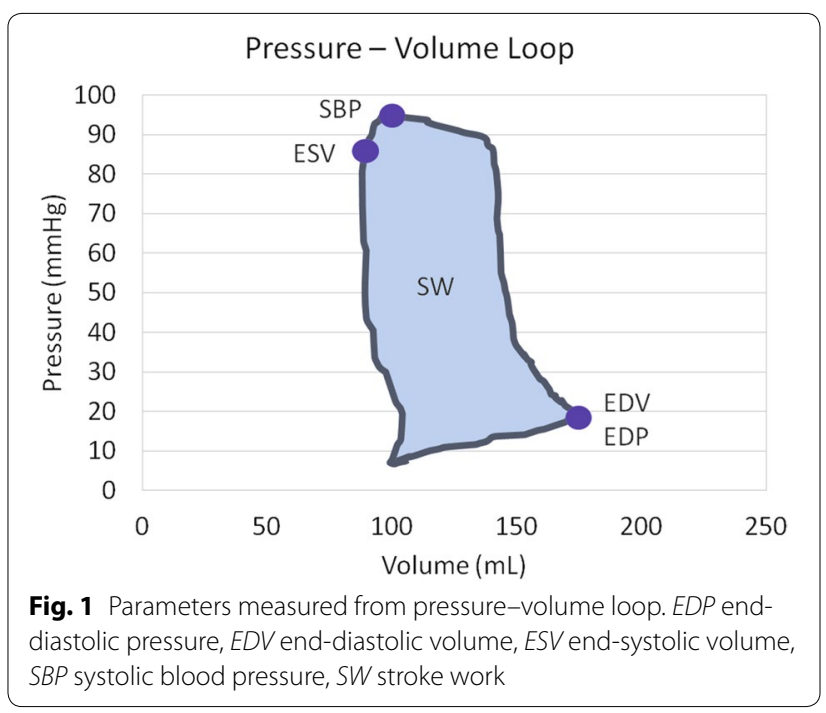

ligation or embolization with subsequent myocardial infarction [19-21]. However, this approach is associated with a very high acute mortality rate [19-21]. Therefore, we developed an alternative model of myocardial hypoxia. Coronary angiography was performed and, according to the specific coronary anatomy in each animal, the largest left main coronary artery branch (left anterior descending artery or left circumflex artery) was identified. Two coronary guide wires were then introduced into the selected vessel. The first wire was used for the placement of a balloon catheter and the second for introduction of an over-the-wire export catheter (Medtronic, USA) with the tip distal to the end of balloon. The entry of the Export catheter was connected to the ECMO circuit between the pump and oxygenator (Fig. 2). After inflation of the balloon, the coronary artery was perfused with venous blood at a rate of approximately $40 \mathrm{~mL} / \mathrm{min}$. Cardiogenic shock with signs of tissue hypoperfusion was defined as a drop in systolic blood pressure to $<100 \mathrm{mmHg}$ and at least one of the following criteria: increase in blood lactate to $>2.0 \mathrm{mmol} / \mathrm{L}$; decrease of mixed venous oxygen saturation to $<50 \%$; or fall in brain tissue oxygen saturation to $<50 \%$. In cases in which the above procedure was insufficient to cause cardiogenic shock, an additional balloon catheter was introduced into the periphery of the second left main coronary artery branch and myocardial infarction was induced in the respective area by inflation of the balloon.

\section{Experimental protocol}

After insertion of all catheters and establishment of ECMO, the animals were stabilized for $10 \mathrm{~min}$. Cardiogenic shock was then induced using the above mentioned procedure. If necessary, defibrillation was performed and 


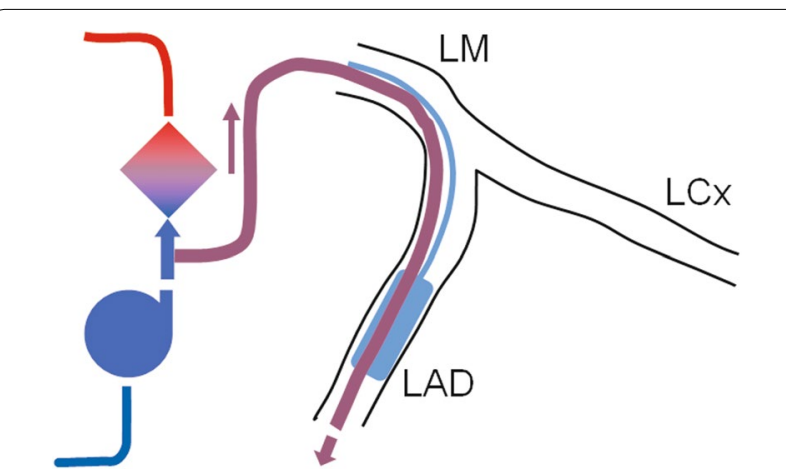

Fig. 2 Induction of regional myocardial hypoxia through perfusion of selected coronary artery by desaturated venous blood. LAD left anterior descending artery, $L C X$ left circumflex artery, $L M$ left main artery

amiodaron $150 \mathrm{mg}$ was administered IV to ensure myocardial electrical stabilization. After development of signs of tissue hypoperfusion (approximately 60-90 $\mathrm{min}$ ) and an additional $10 \mathrm{~min}$ of stabilization, the EBF was gradually increased by $1 \mathrm{~L} / \mathrm{min}$ every $5 \mathrm{~min}$. Once an EBF level of $5 \mathrm{~L} / \mathrm{min}$ was reached, it was maintained for $10 \mathrm{~min}$; subsequently, the EBF was gradually decreased every $5 \mathrm{~min}$ by $1 \mathrm{~L} / \mathrm{min}$. At an EBF level of $1 \mathrm{~L} / \mathrm{min}$, the animals were again stabilized for $10 \mathrm{~min}$ and a second cycle of stepwise EBV increase and decrease was subsequently performed (Fig. 2). Measurements from the end of each 5 min interval were averaged (four data sets per animal) and used for further analysis.

\section{Statistical analysis}

Results are expressed as mean \pm SEM. The differences among individual levels of EBF were analyzed using a repeated-measures one-way ANOVA with Tukey's multiple comparison test, or using the Friedman test with Dunn's multiple comparison test (for data sets without normal distribution); $\mathrm{P}<0.05$ was considered to be statistically significant. All statistical analyses were performed using GraphPad Prism 5.0 software (GraphPad, USA).

\section{Results}

Myocardial hypoxia alone led to extensive myocardial injury sufficient to cause cardiogenic shock in four of five experimental animals. In one animal, an additional coronary artery occlusion was necessary to induce cardiogenic shock. Two animals were defibrillated (one and three attempts needed, respectively) because of ventricular fibrillation. All animals survived myocardial injury and successfully underwent all study procedures. The baseline values after the development of cardiogenic shock were: ${ }_{\mathrm{p}} \mathrm{CO} 2.81 \pm 0.34 \mathrm{~L} / \mathrm{min}$; SBP $60 \pm 7 \mathrm{mmHg}$; LVEF $43 \pm 3 \%$; and HR $94 \pm 4$ beats $/ \mathrm{min}$.

\section{Directly measured parameters}

With increasing EBF, an increase in SBP was observed, from $60 \pm 7 \mathrm{mmHg}$ to $72 \pm 7,81 \pm 6,89 \pm 7$ and $97 \pm 8 \mathrm{mmHg}$, respectively (EBF $1,2,3,4$ and $5 \mathrm{~L} / \mathrm{min}$; $\mathrm{P}<0.001$ ) (Fig. 3a); HR decreased from $94 \pm 4$ beats $/ \mathrm{min}$ to $89 \pm 3,84 \pm 3,80 \pm 2$ and $77 \pm 2$ beats $/ \mathrm{min}$, respectively (EBF $1-5 \mathrm{~L} / \mathrm{min} ; \mathrm{P}<0.001$ ) (Fig. $3 \mathrm{~b}$ ); ${ }_{\mathrm{P}} \mathrm{CO}$ decreased from $2.81 \pm 0.34 \mathrm{~L} / \mathrm{min}$ to $2.49 \pm 0.25,2.21 \pm 0.21$, $1.84 \pm 0.31$ and $1.86 \pm 0.53 \mathrm{~L} / \mathrm{min}$, respectively (EBF 1-5 L/min; $\mathrm{P}=0.005$ ) (Table 1 ); ESV increased from $64 \pm 11 \mathrm{~mL}$ to $70 \pm 11,74 \pm 11,78 \pm 12$ and $83 \pm 14 \mathrm{~mL}$, respectively (EBF $1-5 \mathrm{~L} / \mathrm{min}$; $\mathrm{P}<0.001$ ) (Fig. 3c); EDV did not change significantly $(112 \pm 19,115 \pm 19,116 \pm 19$, $119 \pm 19$ and $123 \pm 20 \mathrm{~mL}$, respectively; EBF $1-5 \mathrm{~L} / \mathrm{min}$, $\mathrm{P}=0.43$ ) (Fig. 3d); and although there was only a numerical increase in EDP from $17.2 \pm 1.4 \mathrm{mmHg}$ to $18.2 \pm 0.7$, $18.6 \pm 1.5,18.9 \pm 2.4$ and $19.0 \pm 2.9 \mathrm{mmHg}$, respectively, these differences were not statistically significant (EBF 1-5 L/min; $\mathrm{P}=0.87$ ) (Fig. 3e). Finally, SW increased from $2096 \pm 342 \mathrm{mmHg} \mathrm{mL}$ to $2510 \pm 335,2752 \pm 346$, $3031 \pm 404$ and $2884 \pm 412 \mathrm{mmHg} \mathrm{mL}$, respectively (EBF 1-5 L/min; P < 0.001) (Fig. 3f).

\section{Calculated parameters}

With increasing EBF, a decrease in SV was observed, from $48 \pm 9 \mathrm{~mL}$ to $45 \pm 9,42 \pm 9,41 \pm 9$ and $40 \pm 8 \mathrm{~mL}$, respectively (EBF $1-5 \mathrm{~L} / \mathrm{min}, \mathrm{P}=0.045$ ) (Fig. $3 \mathrm{~g}$ ); LVEF decreased from $43 \pm 3 \%$ to $39 \pm 2 \%, 36 \pm 3 \%, 34 \pm 3 \%$ and $32 \pm 3 \%$, respectively (EBF $1-5 \mathrm{~L} / \mathrm{min} ; \mathrm{P}<0.001$ ) (Fig. 3h); and ${ }_{\mathrm{LV}} \mathrm{CO}$ decreased from $4.31 \pm 0.40 \mathrm{~L} / \mathrm{min}$ to $3.90 \pm 0.47,3.49 \pm 0.51,3.21 \pm 0.40$ and $2.99 \pm 0.38 \mathrm{~L} /$ min, respectively (EBF $1-5 \mathrm{~L} / \mathrm{min} ; \mathrm{P}<0.001)$ (Table 1 ). The RecV and RecF remained comparable across the different EBF levels (Table 1).

\section{Discussion}

The present study reports for the first time that in cardiogenic shock, EBF during VA ECMO affects invasively measured left ventricular performance parameters in a flow-dependent manner.

As a result of increasing EBF in the failing heart, we observed an increase in SBP and decrease in HR; these changes tended toward the normal values. In particular, elevation of low SBP in cardiogenic shock, together with optimizing tissue perfusion parameters, are the clearest and most easily measurable targets for ECMO therapy. However, it has been repeatedly demonstrated that increased SBP also leads to higher afterload, which may have a deleterious effect on the failing left ventricle [7]. Although a causal relationship between increased afterload and depressed left ventricular function in cardiogenic shock and VA ECMO therapy is more than likely, other factors (i.e., humoral factors or vegetative nervous 

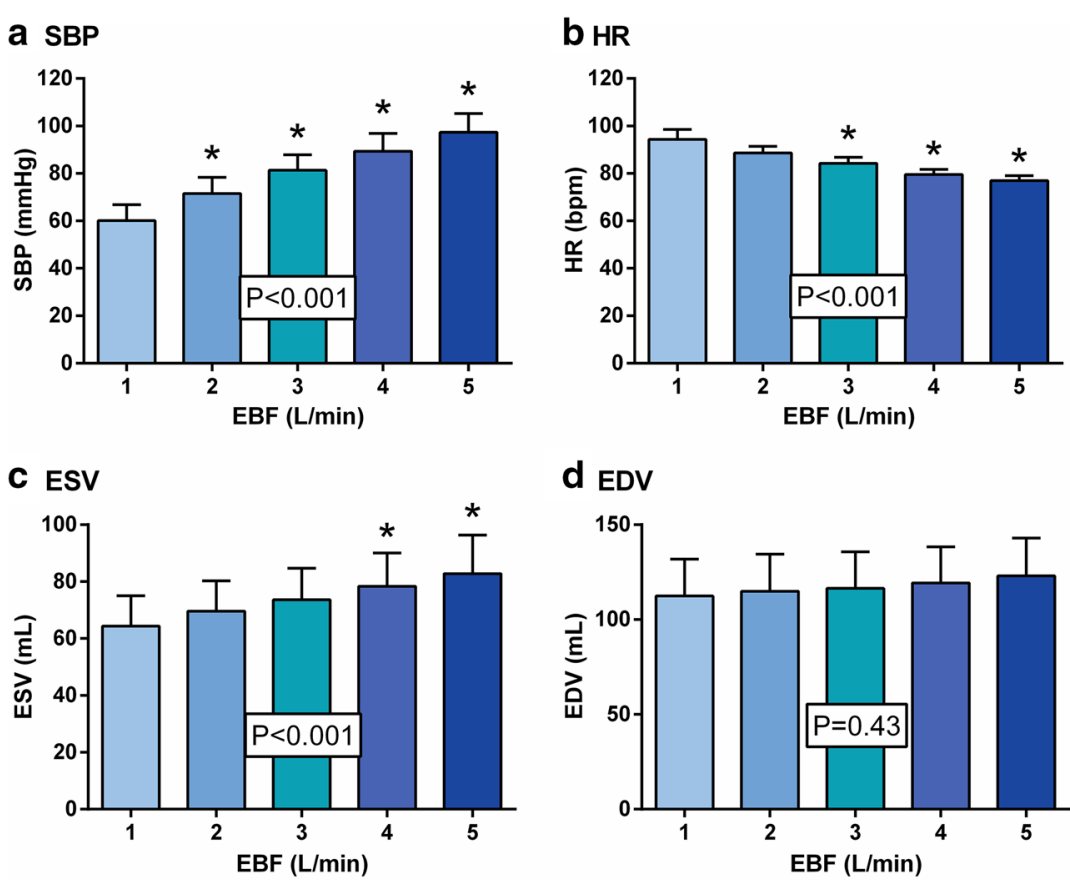

\section{d EDV}

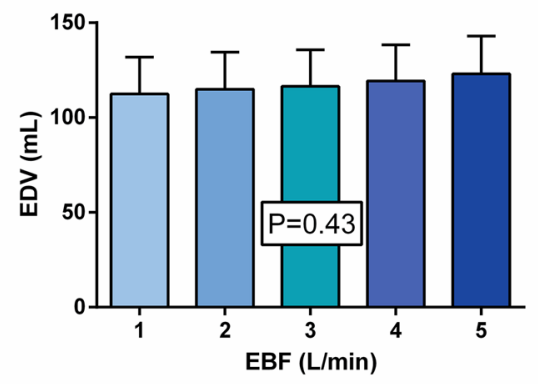

e EDP

f sw
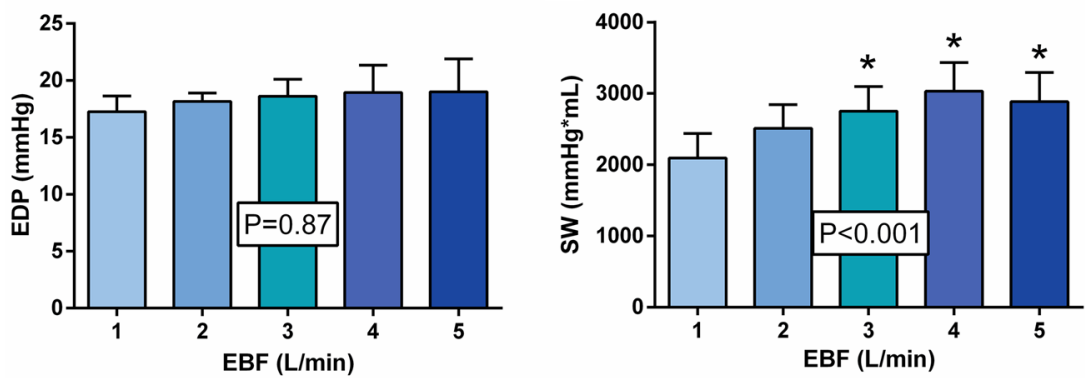

g sv

h LVEF
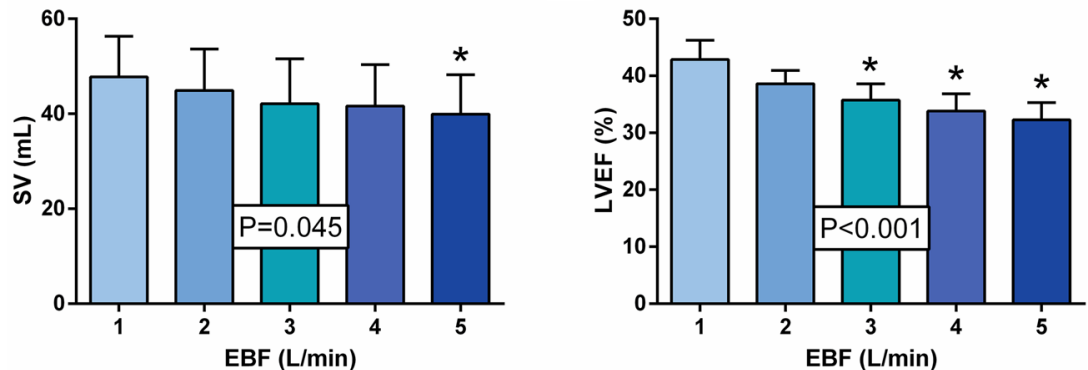

Fig. 3 The effect of venoarterial extracorporeal membrane oxygenation blood flow on selected hemodynamic and left ventricular performance parameters in a porcine model of cardiogenic shock. EBF extracorporeal blood flow, EDP end-diastolic pressure, EDV end-diastolic volume, ESV end-systolic volume, HR heart rate, LVEF left ventricular ejection fraction, SBP systolic blood pressure, SV stroke volume, SW stroke work. ${ }^{*} P<0.05$ compared with value at EBF $1 \mathrm{~L} / \mathrm{min}$

system) may also contribute to this deleterious effect. Nevertheless, with increasing EBF and SBP, we observed an increase in ESV and decrease in SV and LVEF that resulted in decreased cardiac output.
Although EDV and EDP values increased numerically with increasing EBF, these differences did not reach statistical significance. However, EDV and EDP are markedly influenced not only by afterload but also by preload. 
Table 1 The effect of venoarterial extracorporeal membrane oxygenation blood flow on selected hemodynamic parameters in a porcine model of cardiogenic shock

\begin{tabular}{lllllll}
\hline EBF & $\mathbf{1}$ & $\mathbf{2}$ & $\mathbf{3}$ & $\mathbf{4}$ & $\mathbf{5}$ & $\mathbf{P}$ \\
\hline${ }_{\text {LVCO }}$ & $4.31 \pm 0.40$ & $3.90 \pm 0.47$ & $3.49 \pm 0.51^{*}$ & $3.21 \pm 0.40^{*}$ & $2.99 \pm 0.38^{*}$ & $<0.001$ \\
${ }_{\mathrm{P} C O}$ & $2.81 \pm 0.34$ & $2.49 \pm 0.25$ & $2.21 \pm 0.21$ & $1.84 \pm 0.31^{*}$ & $1.86 \pm 0.53^{*}$ & $<0.001$ \\
ReCV & $1.51 \pm 0.24$ & $1.40 \pm 0.41$ & $1.28 \pm 0.42$ & $1.38 \pm 0.28$ & $1.13 \pm 0.37$ & 0.83 \\
ReCF $(\%)$ & $35.0 \pm 4.8$ & $36.0 \pm 7.6$ & $36.6 \pm 7.9$ & $42.8 \pm 4.9$ & $37.9 \pm 10.7$ & 0.57 \\
\hline
\end{tabular}

Values of all parameters, with the exception of RecF, are expressed in L/min

EBF extracorporeal blood flow; ${ }_{L V} \mathrm{CO}$ cardiac output, calculated from stroke volume (SV) and heart rate (HR) using the formula: ${ }_{\mathrm{LV}} \mathrm{CO}=\mathrm{SV}$. HR; ${ }_{\mathrm{p}} \mathrm{CO}$ cardiac output, measured using a pulmonary artery catheter; $\operatorname{RecV}$ recirculation volume, calculated using the formula: $\operatorname{RecV}={ }_{\mathrm{LV}} \mathrm{CO}-{ }_{\mathrm{p}} \mathrm{CO}$; $R e c F$ recirculation fraction, calculated using the formula: $\operatorname{RecF}=\left(\operatorname{RecV} /{ }_{L V} C O\right) \times 100$

* $\mathrm{P}<0.05$ compared with value at EBF $1 \mathrm{~L} / \mathrm{min}$

At the highest EBF level, the right ventricle is almost entirely unloaded and the ${ }_{\mathrm{p}} \mathrm{CO}$ rapidly decreases, which most likely lowers preload on the left ventricle. On the other hand, the preload on the failing left ventricle during VA ECMO may also be influenced by an increased fraction of bronchial circulation, and/or mitral and aortic regurgitation. In particular, aortic regurgitation is typically present in our experimental model due to the insertion of the PV-loop catheter through the aortic valve. However, based on echocardiography evaluation, this regurgitation appears to be of little significance.

To evaluate the effect of bronchial circulation, mitral regurgitation and aortic regurgitation on left ventricular preload, we also calculated values of the parameters of recirculation, RecV and RecF. Interestingly, these parameters were not significantly influenced by EBF levels. This observation may also indicate that recirculation plays a minor role in the development of distension of the overloaded left ventricle, with subsequent severe pulmonary edema, which is frequently observed in patients with severely depressed left ventricular function on high-flow VA ECMO.

Furthermore, we also observed elevation of SW with increased EBF (numerically highest at an EBF level of $4 \mathrm{~L} / \mathrm{min}$ ). This observation indicates that more energy needs to be expended by the left ventricle for each blood ejection at higher levels of EBF. It is unclear whether this increased energy demand is balanced by better coronary perfusion secondary to increased mean arterial pressure.

The occurrence of severe myocardial dysfunction as a result of VA ECMO has been acknowledged for many years. It has repeatedly been described in neonates with respiratory failure or with pulmonary hypertension [11-13], and similar findings were also observed in a lamb model [14]. Karr et al. [22] showed that impaired cardiac performance in infants is directly associated with ECMO therapy and that it is not a consequence of the primary lung disease. These studies are fully concordant with our results showing deterioration of left ventricular performance caused by VA ECMO in a flow-dependent manner. Shen et al. [16] have also shown that perfusion of coronary arteries by desaturated blood from the pulmonary circulation may play a role in the development of left ventricular dysfunction during VA ECMO. This is a highly clinically relevant issue, with risk for not only myocardial but also brain hypoxia. Monitoring coronary blood oxygen saturation is technically difficult in clinical settings; however, near-infrared spectroscopy oximetry offers continuous noninvasive measurement of brain oxygen saturation [23].

It could be argued that the myocardial left ventricular dysfunction that we attribute to ECMO-generated afterload was a consequence of global myocardial hypoxia due to desaturated blood from the pulmonary circulation. While this hypothesis cannot be fully ruled out, we consider it to be unlikely for several reasons: first, healthy animals with normal pulmonary function were used, and it is unlikely that severe pulmonary edema would develop within a few hours under our protocol; in addition, no signs of pulmonary edema (fluoroscopy, pulmonary mechanics) were observed throughout the study; second, we did not detect contractile dysfunction in nonaffected segments of the myocardium; and, finally, right ear $\mathrm{SpO}_{2}$ was maintained within normal limits.

Numerous studies have also focused on adult patients with severe myocardial dysfunction undergoing VA ECMO, usually with emphasis on the distension of the overloaded left ventricle, which is frequently associated with severe pulmonary edema and represents a serious clinical issue [7-10]. We did not observe the development of this critical condition in our study, even at the highest level of EBF. We also did not detect significant increases in EDV and EDP, although we observed numerically increased values in these parameters. There are 
several possible explanations for this discordance: first, we used an animal model of acute cardiogenic shock with the follow-up limited to approximately $150 \mathrm{~min}$, and this interval may be too short for the development of left ventricular distension; second, left ventricular systolic function was not sufficiently impaired in our study to develop left ventricular distension; and, finally, the compliance of otherwise healthy left ventricle with acute regional hypoxic/ischemic injury is too low to allow distension.

Our results are consistent with the study by Aissaoui et al. [17] showing improvement in several echocardiographical parameters determining left ventricular performance in cardiogenic shock patients with decreasing VA ECMO flow.

The present study had several limitations. First, we used only five animals; however, the present research was a pilot study using an alternative model of cardiogenic shock that increases the survival rate immediately following extensive acute myocardial injury. Second, the extent of myocardial injury was different due to individual coronary anatomy; on the other hand, all animals fulfilled the defined criteria of cardiogenic shock with signs of tissue hypoperfusion. Third, we used young and otherwise healthy animals; therefore, our experimental settings simulate clinical conditions in patients with cardiogenic shock caused by acute myocardial infarction rather than severe myocarditis or advanced dilated cardiomyopathy.

\section{Conclusions}

Our results demonstrate that increasing EBF in cardiogenic shock during VA ECMO may cause impairment of left ventricular performance in a flow-dependent manner. These data indicate that the optimal VA ECMO flow in cardiogenic shock should be as low as possible to allow adequate tissue perfusion.

\section{Authors' contributions}

PO, MMI, AK, PN: study conception and design; PH, SL, DV, MJ, MH, TS, HP, SS: data acquisition, analysis, and interpretation; PO: manuscript drafting; MMI, AK, MMa: critical revision; OK, PN: final approval of the manuscript. All authors read and approved the final manuscript.

\section{Author details}

${ }^{1}$ Cardiovascular Center, Na Homolce Hospital, 15030 Prague, Czech Republic. ${ }^{2}$ Department of Physiology, First Faculty of Medicine, Charles University in Prague, Prague, Czech Republic. ${ }^{3}$ Faculty of Biomedical Engineering, Czech Technical University in Prague, Prague, Czech Republic.

\section{Acknowledgements}

This study was supported by a Grant from the Czech Ministry of Health, Nr. 12153, and by an Institutional Grant MH CZ-DRO (Nemocnice Na Homolce-NNH, 00023884).

\section{Compliance with ethical guidelines}

\section{Competing interests}

The authors declare that they have no competing interests.
Received: 1 February 2015 Accepted: 11 August 2015

Published online: 15 August 2015

\section{References}

1. Abrams D, Combes A, Brodie D. Extracorporeal membrane oxygenation in cardiopulmonary disease in adults. J Am Coll Cardiol. 2014;63:2769-78.

2. Werdan K, Gielen S, Ebelt H, Hochman JS. Mechanical circulatory support in cardiogenic shock. Eur Heart J. 2014;35:156-67.

3. Annich G, Lynch W, MacLaren G, Wilson J, Bartlett R, editors. ECMO. Extracorporeal cardiopulmonary support in critical care. 4th edn. Ann Arbor: Extracorporeal Life Support Organization; 2012.

4. Beurtheret S, Mordant P, Paoletti X, Marijon E, Celermajer DS, Leger P, Pavie A, Combes A, Leprince P. Emergency circulatory support in refractory cardiogenic shock patients in remote institutions: a pilot study (the cardiac-RESCUE program). Eur Heart J. 2013;34:112-20.

5. PranikoffT, Hirschl RB, Steimle CN, Anderson HL 3rd, Bartlett RH. Efficacy of extracorporeal life support in the setting of adult cardiorespiratory failure. ASAIO J. 1994;40:M339-43.

6. Combes A, Leprince P, Luyt CE, Bonnet N, Trouillet JL, Leger P, Pavie A, Chastre J. Outcomes and long-term quality-of-life of patients supported by extracorporeal membrane oxygenation for refractory cardiogenic shock. Crit Care Med. 2008;36:1404-11.

7. Fuhrman BP, Hernan LJ, Rotta AT, Heard CM, Rosenkranz ER. Pathophysiology of cardiac extracorporeal membrane oxygenation. Artif Organs. 1999;23:966-9.

8. Sidebotham D, Allen S, McGeorge A, Beca J. Catastrophic left heart distension following initiation of venoarterial extracorporeal membrane oxygenation in a patient with mild aortic regurgitation. Anaesth Intensive Care. 2012;40:568-9.

9. Soleimani B, Pae WE. Management of left ventricular distension during peripheral extracorporeal membrane oxygenation for cardiogenic shock. Perfusion. 2012;27:326-31.

10. Barbone A, Malvindi PG, Ferrara P, Tarelli G. Left ventricle unloading by percutaneous pigtail during extracorporeal membrane oxygenation. Interact CardioVasc Thorac Surg. 2011;13:293-5.

11. Hirschl RB, Heiss KF, Bartlett RH. Severe myocardial dysfunction during extracorporeal membrane oxygenation. J Pediatr Surg. 1992;27:48-53.

12. Kimball TR, Daniels SR, Weiss RG, Meyer RA, Hannon DW, Ryckman FC, Tian J, Shukla R, Schwartz DC. Changes in cardiac function during extracorporeal membrane oxygenation for persistent pulmonary hypertension in the newborn infant. J Pediatr. 1991;118:431-6.

13. Berdjis F, Takahashi M, Lewis AB. Left ventricular performance in neonates on extracorporeal membrane oxygenation. Pediatr Cardiol. 1992;13:141-5.

14. Pyles LA, Gustafson RA, Fortney J, Einzig S. Extracorporeal membrane oxygenation induced cardiac dysfunction in newborn lambs. J Cardiovasc Transl Res. 2010;3:625-34.

15. Shen I, Levy FH, Vocelka CR, O'Rourke PP, Duncan BW, Thomas R, Verrier ED. Effect of extracorporeal membrane oxygenation on left ventricular function of swine. Ann Thorac Surg. 2001;71:862-7.

16. Shen I, Levy FH, Benak AM, Rothnie CL, O'Rourke PP, Duncan BW, Verrier ED. Left ventricular dysfunction during extracorporeal membrane oxygenation in a hypoxemic swine model. Ann Thorac Surg. 2001;71:868-71.

17. Aissaoui N, Guerot E, Combes A, Delouche A, Chastre J, Leprince P, Leger P, Diehl JL, Fagon JY, Diebold B. Two-dimensional strain rate and Doppler tissue myocardial velocities: analysis by echocardiography of hemodynamic and functional changes of the failed left ventricle during different degrees of extracorporeal life support. J Am Soc Echocardiogr. 2012;25:632-40.

18. MacLaren G, Dodge-Khatami A, Dalton HJ, Writing C, MacLaren G, Dodge-Khatami A, Dalton HJ, Adachi I, Almodovar M, Annich G, et al. Joint statement on mechanical circulatory support in children: a consensus review from the Pediatric Cardiac Intensive Care Society and Extracorporeal Life Support Organization. Pediatr Crit Care Med. 2013;14:S1-2.

19. Schmitto JD, Mokashi SA, Lee LS, Popov AF, Coskun KO, Sossalla S, Sohns C, Bolman RM 3rd, Cohn LH, Chen FY. Large animal models of chronic heart failure (CHF). J Surg Res. 2011;166:131-7. 
20. Dixon JA, Spinale FG. Large animal models of heart failure: a critical link in the translation of basic science to clinical practice. Circ Heart Fail. 2009;2:262-71.

21. Abarbanell AM, Herrmann JL, Weil BR, Wang Y, Tan J, Moberly SP, Fiege JW, Meldrum DR. Animal models of myocardial and vascular injury. J Surg Res. 2010;162:239-49.

22. Karr SS, Martin GR, Short BL. Cardiac performance in infants referred for extracorporeal membrane oxygenation. J Pediatr. 1991;118:437-42.
23. Ostadal P, Kruger A, Vondrakova D, Janotka M, Psotova $H$, Neuzil P. Noninvasive assessment of hemodynamic variables using near-infrared spectroscopy in patients experiencing cardiogenic shock and individuals undergoing venoarterial extracorporeal membrane oxygenation. J Crit Care. 2014;29(690):e611-95.

\section{Submit your next manuscript to BioMed Central} and take full advantage of:

- Convenient online submission

- Thorough peer review

- No space constraints or color figure charges

- Immediate publication on acceptance

- Inclusion in PubMed, CAS, Scopus and Google Scholar

- Research which is freely available for redistribution

Submit your manuscript at

www.biomedcentral.com/submit

(O) Biomed Central 